\title{
Collective Phronesis in Business Ethics Education and Managerial Practice: A Neo-Aristotelian Analysis
}

\author{
Kristján Kristjánsson ${ }^{1}$
}

Received: 14 May 2021 / Accepted: 30 July 2021 / Published online: 8 August 2021

(c) The Author(s) 2021

\begin{abstract}
The aim of this article is to provide an overview of various discourses relevant to developing a construct of collective phronesis, from a (neo)-Aristotelian perspective, with implications for professional practice in general and business practice and business ethics education in particular. Despite the proliferation of interest in practical wisdom within business ethics and more general areas of both psychology and philosophy, the focus has remained mostly on the construct at the level of individual decision-making, as in Aristotle's Nicomachean Ethics. However, he also made intriguing remarks about phronesis at the collective level in his Politics: remarks that have mostly eluded elaboration. The aim of this article is practical and revisionary, rather than exegetical and deferential, with respect to Aristotle. Nevertheless, just as most of the literature on individual phronesis draws on Aristotle's exposition in the Nicomachean Ethics, the obvious first port of call for an analysis of collective phronesis is to explore the resources handed down to us by Aristotle himself. The lion's share of this article is, therefore, devoted to making sense of Aristotle's somewhat unsystematic remarks and the lessons we can draw from them about collective managerial phronesis and business ethics education.
\end{abstract}

Keywords Collective phronesis $\cdot$ Aristotle $\cdot$ Managerial (business) practice $\cdot$ Wisdom of crowds $\cdot$ Business ethics education

The aim of this article is to provide a broad overview of various discourses relevant to developing a construct of collective phronesis, from a broadly (neo)-Aristotelian perspective, with implication for professional practice, in general, and business practice as well as business ethics education, in particular. Despite the recent proliferation of interest in practical wisdom as phronesis within professional ethics, including business ethics, and more general areas of both psychology and philosophy, the focus has remained mostly on the construct at the level of individual decision-making, much as the forebear of the phronesis concept, Aristotle, did in the Nicomachean Ethics. However, he also made intriguing remarks about phronesis at the collective level in his Politics: remarks that have mostly eluded elaboration outside of small pockets of Aristotelian scholarship. The aim of this article is practical and revisionary, rather than exegetical and deferential, with respect to Aristotle; hence the 'neo-' in the

Kristján Kristjánsson

k.kristjansson@bham.ac.uk

1 Jubilee Centre for Character and Virtues, School of Education, University of Birmingham, Edgbaston, Birmingham B15 2TT, UK title. Nevertheless, just as most of the standard literature on phronesis takes its cue from Aristotle's exposition in the Nicomachean Ethics, the obvious first port of call for an analysis of collective phronesis is to explore the resources handed down to us by Aristotle himself. The lion's share of this article is, therefore, devoted to making sense of Aristotle's somewhat unsystematic remarks and the lessons we can draw from them: lessons that are, arguably, quite different from the ones typically elicited in the scholarship on Aristotelian political theory.

I begin, in the Sect. "Individual and Collective Phronesis: Some Conceptual Preliminaries", with a critical overview of some of the recent literatures on phronesis and how those relate to various other discourses to which they are not normally connected, such as those on the 'wisdom of crowds'. The Sect. "What is Aristotle's Take on Collective Phronesis?" excavates those resources in Aristotle that might, initially at least, be considered most germane to the topic of phronetic joint decision-making: his account of friendships in the Nicomachean Ethics and of the 'wisdom of the multitude' in the Politics. The Sect. 'Interpreting the Accumulation Argument for Collective Phronesis" subjects those resources, and the secondary literature on them, to critical 
scrutiny, the upshot of which will be that while Aristotle's potential contribution to the ideal of deliberative democracy has been over-emphasised, he does make some salutary claims about the nature of practically wise joint decisionmaking, whose relevance extends beyond political governance into areas of business ethics education, administration and management. As Aristotle's account of collective phronesis is lacking in detail and nuance, the Sect. "The Components of Collective Managerial Phronesis" offers speculative hypotheses about how his componential theory of individual phronesis could be extended to the joining of phronetic dots from different individuals to make up collective managerial phronesis. Finally, the Sect. "Some Practical Business Applications" elicits some practical, including educational, lessons about how collective phronesis could be enhanced and practised at the collective (business-ethics-educational and organisational) level.

Readers must be pre-warned that this article is unapologetically cross-disciplinary and geared towards breadth rather than depth. When beginning research into the construct of collective phronesis, I was struck by the apparent absence of any comprehensive overview of the field or, more specifically, any study charting the outlines of a broad terrain, the sub-areas of which could then be mapped out in more targeted studies. The current article aims at providing such an overview or initiation into a potentially novel discourse which other researchers would then be encouraged to flesh out and finesse.

\section{Individual and Collective Phronesis: Some Conceptual Preliminaries}

Aristotle (1985) famously analyses various modes of thinking, one of which is contemplation (theoria) about abstract and unchanging things. The intellectual virtue representing excellence in this area is theoretical wisdom (sophia), which operates mostly at the vantage point of secure distance from practical concerns. Diametrically opposed to theoria is poiesis: thinking and acting in the area of production. The intellectual virtue in this area is techné: excellence or refined practical skill in making things. Placed in between sophia and techné, but significantly closer to the latter, is the virtue of practical wisdom (phronesis), operating in the sphere of praxis: of (thinking about) action, that is about 'doing' as distinct from 'making'. Although Aristotle likes to compare phronesis to a skill, such as playing the flute, he remains clear on the distinctions between the two. The key difference is that the excellence of techné lies in the product or outcome of the activity, but the excellence of phronesis lies in the process of thinking and acting (although beneficial outcomes will also follow if all goes well). To complicate matters, Aristotle describes phronesis as a subspecies of a more general cognitive capacity of 'cleverness' or 'calculation' (deinotes): the intellectual virtue of being able to figure out the proper actions 'that tend to promote whatever goal is assumed and to achieve it. If, then, the goal is fine, cleverness is praiseworthy, and if the goal is base, cleverness is unscrupulousness; hence both [phronetic] and unscrupulous people are called clever' (Aristotle, 1985, p. 169 [1144a23-28]). As distinct from general deinotes, phronesis concerns issues that fall under the moral sphere, which for Aristotle (who did not operate with a standardly modern concept of 'the moral' as 'the prosocial') meant the sphere of ethical character, and also under the sphere of civic (political) activity.

So much has been written about phronesis of late, not least in business ethics journals, that a detailed characterisation would be surplus to requirements (although I do return to its detailed components in the Sect. "The Components of Collective Managerial Phronesis"). Suffice it to say here that phronesis plays the role of a metacognitive virtue of discernment, deliberation, reflection and arbitration in Aristotle's virtue system; it synthesises the demands of the different moral and civic virtues and adjudicates in cases of (apparent) conflicts between them (Kristjánsson et al., 2021). Although there is no single overarching substantive master-virtue in Aristotle's system, like justice for Plato, phronesis operates as the glue which holds the whole system together or, to use another metaphor, serves as the conductor harmonising the whole virtue orchestra.

After slipping from the academic map for centuries-possibly because of the attractions of instrumentalist (Humean/ Weberian) and formalist (Kantian/Kohlbergian) thinkingphronesis has experienced a resurgence of late within philosophy (Annas, 2011; Russell, 2009), education (Kristjánsson, 2021), psychology (Darnell et al., 2019; Fowers et al., 2021; Grossmann et al., 2020; Schwartz \& Sharpe, 2010) and general social-science theory/methodology (Flyvbjerg, 2001)but perhaps most importantly, for present purposes, within sub-areas of professional ethics such as medicine (Kaldjian, 2014) and business (Alzola et al., 2020). Within business ethics and leadership/administration studies, we already have at least two handbooks available (edited by Küpers \& Pauleen, 2013; Schwartz et al., 2021), a recent comprehensive literature review (Ames et al., 2020) and a new typology of managerial phronesis (Steyn \& Sewchurran, 2021).

The latter-day proliferation of phronesis research has been motivated by various factors. In philosophy, it has served as the natural outgrowth of the rising tide of virtue ethics, typically inspired by Aristotle (Annas, 2011). In psychology, it has been elicited by an interest in trying to solve 
the infamous 'gappiness problem' in moral developmental theory-of what bridges the gap between moral knowledge and moral action (Darnell et al., 2019) — and by a more general concern with making sense of a practical concept of wisdom at work in human affairs (Grossmann et al., 2020). While some of those same aspirations have cascaded into professional discourse, for instance within business ethics, the retrieval of phronesis research there admits of more domain-specific explanations.

In the last 25 years or so, virtue ethics has gradually equalled or even surpassed deontology and utilitarianism as the theory of choice within academic business ethics, although that scholarly interest has not always percolated down to actual business practice or even business ethics education (Huo \& Kristjánsson, 2018). Solomon's pioneering work (e.g. 1992) acted as a catalyst for this development, but various formidable business ethics scholars have followed in his wake (see e.g. Koehn, 1995; Sison et al., 2018; Beadle \& Moore, 2018; Alzola et al., 2020). Many of these scholars have given pride of place to phronesis in their virtue ethical theorising, and that may be part of the explanation for the appeal of such theorising. This explanation would tie in, among other things, with a perception of escalating corporate scandals and organisational failures, culminating in the 2007-2008 financial crisis: events that have undermined beliefs both in scientific (e.g. Taylorite) managerial structures and the power of formal rules and codes of conduct (be those deontological or modelled on Aristotle's virtues of techné and deinotes) to guide professional behaviour. This perception has gone hand in hand with a growing concern among professionals about the loss of the ideal of professional expertise and its replacement with instrumentalist, managerialist orthodoxies that pander to a mistaken confidence in scientific certainties (Sellman, 2012), supplanting personal responsibility and contextual discernment with formalistic accountability and compliance. The concept of phronesis has thus been seen to fill a void in increasingly impoverished conceptualisations of the nature of professional work.

As a case in point, various reports of ethical perceptions within U.K. professions have indicated a disillusionment with the content of professional ethics classes. Business students, for instance, complain about the content of business ethics classes being either too abstract (about lofty principles such as corporate social responsibility) or too mundane (just about compliance) with insufficient attention being paid to the 'moral middle' where business people encounter dilemmatic situations in dealings with customers, and how to navigate such situations through the use of personal character virtues, orchestrated by practical wisdom (Huo \& Kristjánsson, 2018). This is a crucial point, because from the perspective of Aristotelian character education, phronesis development is the main goal of such education in early adulthood and must form the linchpin of all business ethics education. ${ }^{1}$

Arguably, however, the resurrection of phronesis in professional ethics has been hampered by two subtle, but significant, departures from the Aristotelian concept that has been under re-examination in philosophy and psychology. Those departures have been fanned on the one hand by deference to the work of Alasdair MacIntyre and on the other by what could perhaps be called a 'postmodern impulse'. Quite a lot of recent work on phronesis in business ethics, for example, draws on MacIntyre's (1981) notion of practice (see e.g. Beadle \& Moore, 2018). That notion is substantially different from Aristotle's praxis, inter alia because it includes a wider range of intrinsically valuable activities than would fall under the sphere of the ethical: say, procedural considerations by a business manager on how to solve personality clashes within a team she manages. MacIntyre's concept is also less universalist than Aristotle's and more sociological or Hegelian (Kristjánsson, 2015). The incentive in professional ethics for departing from Aristotle often seems to be that of making sense of the uncodifiability of a range of professional activities that do not, strictly speaking, fall under the category of ethics. However, this departure was never necessary because Aristotle already had at his disposal a sub-concept of techné that allows for uncodifiability. So while expertise in techné is often straightforward and codifiable (you just follow a predetermined plan to succeed: e.g. in producing a standard chocolate cake), some areas of techné are contingently uncodifiable, for example, the skills of a ship's captain or an army general (Kristjánsson, 2007, Chap. 11). To add to the disarray in the field, MacIntyre himself has subsequently refused to grant some of the spheres of activity his followers are most eager to consider 'practices' that very status-for instance business and teaching-preferring to refer to those as techné (MacIntyre \& Dunne, 2003). Paradoxically, therefore, the person most immediately responsible for the retrieval of phronesis research within professional ethics, MacIntyre, appears to have steered the discourse off course in a number of ways.

More inimical to the task of reviving the Aristotelian concept of phronesis has been what I referred to above as a postmodern impulse. That impulse is evidenced in accounts

\footnotetext{
1 Notice that even social intuitionists like Jonathan Haidt might agree with the Aristotelian point about the fundamental role of phronesis cultivation in business ethics education. They would not, however, see the role of phronesis as that of helping students make good decisions, either individually or collectively (as those have already been made by non-deliberative intuitive thrusts from the emotional system), but rather in helping them justify those decisions retrospectively. The salience of phronesis thus becomes social rather than epistemological or moral. See further in Sperber and Mercier (2012).
} 
of phronesis reducing it to some sort of mysterious intuitive artistry that does not admit of any truths and falsehoods and, in the end, comes down to nothing more than individual subjective discretion (or even aesthetic appreciation). On those accounts, phronesis is a fuzzy and indeterminate concept, referring to an elusive capacity 'to think on one's feet [...] experiment $[\ldots]$ and let one's logos hang loose' (Caputo, 1993, p. 101). Kemmis (2012), who is perhaps the most coherent representative of this view, talks about phronesis as belonging to an enigmatic 'negative space for knowledge' (2012, p. 155), rather than being a construct that can be given a positive, objective specification.

What goes amiss here is that Aristotle was a moral realist, believing that phronetic ethical judgement admits of true or false answers (1985, p. 151 [1139bl2-13]). For him, such judgements do not evaluate subjectively an independent realm of facts but rather describe an objectively existing realm of ethical truths. The perfect phronimos, described in Aristotle's Politics as 'a god among men' (1944, p. 241 [1284a10-11]) and the ideal ruler in a utopian monarchy, would always know how to get things right in ethically tricky or dilemmatic situations. Thus, such situations are not essentially uncodifiable. However, because no perfect phronimos of this kind exists in the real world, and because of how messy that world is in terms of varied situational contexts and individual dispositions, we can only aspire to phronetic approximations of the ultimate objective truths. Hence, in the world in which we happen to live, phronesis is contingently uncodifiable. ${ }^{2}$ One way to put this is to say that phronesis signals the epistemological acknowledgement of a tenuous access to an ontological reality that nonetheless exists. To be sure, the theorists who wish to fetishise moral uncertainty and ambivalence in the name of phronesis would complain that this realist assumption betrays a 'hope for another version of techné' (Kemmis, 2012, p. 153) in the ethical sphere. However, what they fail to appreciate is that the main variable distinguishing phronesis from techné was never, for Aristotle, that of uncodifiability. As already noted, he made space for areas of (contingently) uncodifiable techné also. The crucial difference lies rather in the products of techné only being extrinsically valuable, whereas the products of phronesis are intrinsically valuable (in terms

\footnotetext{
2 The distinction between phronesis being essentially uncodifiable and only contingently uncodifiable may seem pedantic, given Aristotle's contention that no person in the real world could have the oversight needed to codify it. However, it is vital to make this distinction to fend off the impression, created by the postmodern take on phronesis, that Aristotle was an ethical anti-realist and that uncodifiability is somehow an advantageous quality of an ethical construct.
}

of the activity itself, independent of further external benefits for, say, prosociality or favourable business outcomes ${ }^{3}$ ).

This brief detour into 'departures' from Aristotelian orthodoxy has been meant to serve as a reminder that there are various different conceptions of the concept of phronesis swirling around in the academic literature. Despite the preponderance of alternative conceptions in the current business ethics literature, in particular, the remainder of this article will be concerned with the original Aristotelian conception only.

Now, although even those who depart from the Aristotelian conception tend to at least pay lip service to the Aristotelian texts, the odd thing is that what gets referred to is almost exclusively the account of phronesis from the Nicomachean Ethics. This is odd because in this worknotwithstanding its emphasis on the communal contexts of good character-Aristotle talks about phronesis solely as an intellectual virtue of an individual deliberating about quandaries involving moral virtues. In the Politics, however, Aristotle extends this discussion to that of phronetic rulers grappling with civic virtues at the state level. Given that the 'states' Aristotle studied were city-states, most (apart from Athens and a few others) with less than 1000 citizens, those resembled more modern medium-sized companies or professional institutions such as hospitals and universities than contemporary mega-states. Indeed, one of the fathers of virtue-based business ethics, Bob Solomon (1992), very fittingly compared the city-states of ancient Greece to modern firms. ${ }^{4}$ As corporate and professional decision-making nowadays takes place to a large extent at the collective rather than the individual level-through boards of directors or teams of professionals-Aristotle's reflections on collective phronesis seem at least as relevant to contemporary contexts as his account of individual phronesis. The two fundamental questions to be pondered in the following are, therefore,

\footnotetext{
3 Thus, baking a cake does not have value for the baker if the cake does not materialise for some reason, for example, because a vital ingredient is missing. However, reflecting virtuously on an ethical quandary and reaching the right decision has value for the agent, as an exhibition of a flourishing-constitutive activity, even if the agent is debarred, for some reason, from acting on the decision. Moreover, while baking is an optional activity from an ethical point of view, phronetic deliberation is mandatory.

4 Telling against this comparison are the frequent contrasts Aristotle draws between merely banausic and commercial enterprises versus the more elevated goals of the state (as a virtue-preserving and virtue-enhancing entity). However, in recent years more and more firms are incorporating virtue-relevant goals into their mission statements, such as those of ethical responsibility and sustainability. This is why, in the Sect. "The Components of Collective Managerial Phronesis" below, I draw on the example of students who plan to establish an ethically responsible business venture. There is thus a case for arguing that Solomon's analogy is even more relevant today than it was in 1992.
} 
about (1) how phronesis (ideally) operates at the collective level and (2) how it can be enhanced at that level.

Before delving into Aristotle's texts, some additional clarifications are needed about links that can —or cannotbe forged with contemporary literatures. First, what I am interested in here is collective phronesis qua joint phronetic decision-making. A recent paper by Conroy et al. (2021) uses the term 'collective phronesis' profusely to describe the aggregated phronesis of a group of professionals across a series of different moral virtues they infuse with phronesis by finding their respective 'golden means'. Aggregated individual phronesis is an interesting topic but remains outside of the current purview which is about more than just the sum of parts. More specifically, it is about what Landemore (2012, p. 8) characterises as 'an emergent phenomenon', not just 'the amplification of individual wisdom'. Second, there is a salient distinction drawn in the recent review paper by Ames and colleagues, on phronesis in business administration and organisations (2020), between phronetic decisions in terms of 'amplitude': individual, group/organisational and macro/societal. 'Amplitude' in this context can refer to the level at which decisions are taken, the set of people affected by the decision or whether the decision is jointly made or not, and then by whom. Since these three senses are not kept distinct by the authors, they miss the chance to address collective phronesis in the specific sense given to it in the current article. Hence, I do not count this review paper as an exception to the rule of failing to carve out a unique account of collective phronesis in the business ethics literature. Third, especially for an author as interested in developmental issues as Aristotle was, there is a thin line between (a) truly joint phronetic decision-making and (b) individual phronetic decision-making, assisted by-or executed in collaboration with - a close friend or a mentor. Although it is, strictly speaking, only (a) that is on the current agenda, I cannot avoid saying something about (b) also at the beginning of the following section.

Rather than tarring the whole of the professional ethics literature with the same brush, it must be mentioned here that collective phronesis, in the true Aristotelian sense, has been explored in a few places before. I would in particular mention a chapter by Schwarz and Lappalainen (2020) in which they helpfully discuss joint decision-making in the context of police ethics and police ethics education; for example, drawing on the way in which police partners control riots. Within the business literature, the most direct exploration of collective phronesis has probably been through the work of the Japanese business scholar Ikujiro Nonaka on collaborative knowledge creation within companies (see e.g. Scalzo \& Fariñas, 2018). It is understandable that special attention is being paid to synergic features of phronesis in Asian cultures, already steeped in the idea of an interdependent self-concept (Markus \& Kitayama, 1991).
In any case, I will be returning to some of Nonaka's insights, especially about the corporate context or space required to facilitate collective phronesis, in the Sect. "Some Practical Business Applications".

Lurking outside the borders of the fairly narrowly circumscribed literatures mentioned already lies a huge terrain of research within business, economics and broader decisiontheory upon which the concept of collective phronesis could be brought to bear. I only have space to mention some examples in passing here; but I will be returning to some of them in the final section. The most obvious point of contact would be with the 'wisdom of crowds': an ideal harking back all the way to Galton (1907) but revived with considerable force, and given empirical backing, in Surowiecki's (2004) bestseller. Surowiecki makes a distinction between three senses of the term 'wisdom of crowds', which he refers to as cognition, coordination and cooperation. The first two forms have to do with non-deliberative forms of collective wisdom: the ability of crowds to make better predictions about matters of fact, such as the weight of a fat ox or the true worth of a stock, than even expert individuals (through the so-called 'miracle of aggregation'); and the capacity of people to coordinate their behaviours spontaneously (such as passing effortlessly through a busy railway station) to secure better outcomes than any intelligent external controller would. We could call those 'thin' wisdom procedures. 'Thicker' procedures involve deliberative collaboration between individuals, thus bringing the wisdom of crowds into the fold of Aristotelian phronesis. Surowiecki, however, spends less time exemplifying those processes in his book.

Even further afield lies a lively research field on symbiotic or collective intelligence (MIT runs a well-known 'Center for Collective Intelligence'). However, this discursive field is almost entirely confined to what Aristotle would call 'cleverness' (deinotes) and can thus be ignored with impunity here. Closer to present concerns is the field of 'organisational wisdom' (see e.g. Rooney, 2013). However, that concept is considerably wider than 'collective phronesis', incorporating both deliberative and non-deliberative processes. Finally, at the highest level of philosophical abstraction, the concept of collective phronesis is theoretically parasitic on the very possibility of 'collective agency': a phenomenon studied within both standard analytic philosophy and continental phenomenology (Schwarz \& Lappalainen, 2020).

What stands out at the end of this first section is that the concept of collective phronesis in Aristotelian virtue ethics potentially cuts across and ties together a motley array of theories and research standpoints both within and outside of professional ethics and the standard business ethics literature. While the following discussion will, by necessity, be selective and focus mainly on lessons to be learned from Aristotle himself, it is worth bearing in mind that any such lessons could potentially have repercussions that extend far 
beyond standard business ethics or even general ethical theorising, more broadly construed.

\section{What is Aristotle's Take on Collective Phronesis?}

The title of this section was deliberately framed such as to avoid indicating that it would summarise Aristotle's own words about collective phronesis, because it so happens that he never uses this term. An account of Aristotle's own take will thus have to be pieced together obliquely from various places in his corpus, especially the Politics. However, it is instructive to begin with his account of friendship from the Nicomachean Ethics, as that is the place where he is most explicit about interdependent character development.

Aristotle famously makes a qualitative distinction between three kinds of friendship, but only the most 'complete' one need concern us presently: 'character friendship'. The most 'perfect' form of character friendships is enacted between fully and equally developed phronimoi who-while not having much left to learn from one another-mutually acknowledge, affirm and enjoy each other's display of virtuous character. For present purposes, however, the less 'perfect' sub-forms of character friendship are more relevant: namely, where the friends are either not equal in virtue or both aspiring, rather than fully developed, phronimoi. In the context of business ethics education, we can envisage a character friendship between a student and an experienced tutor as her moral exemplar, or between two students who aspire to ethical business practices but are still lacking in some of the relevant virtues and try to help each other progress characterologically.

Aristotle makes it abundantly clear that the raison d'être of such 'complete' but 'imperfect' friendships is educational. Indeed, his account of the educational value of character friendships may go some distance towards solving the puzzle of why he says so little about the methods of phronesis development in the sections of phronesis itself: namely, that he reserved it for his friendship theory. Character friends become 'better from their activities and their mutual correction' as 'each moulds the other', and through this mutual moulding they become 'more capable of understanding and acting' (Aristotle, 1985, pp. 266 and 208 [1172a11-14 and 1155a15-16]). Friendship of this kind educates by being, in various ways, knowledge-enhancing, virtue-enhancing and life-enhancing, through friends acting as each other's procreators on the trajectory towards full phronesis and helping each other make wise choices. Aristotle offers various helpful distinctions along the way, such as that of learning from an equal but not fully developed friend as a soulmate, and from a superior friend as a mentor, versus learning from a more distant (heroic) non-friend as a role model (Kristjánsson, 2020).

These lessons are highly relevant for modern business ethics education because, when probed about how such education could be improved and made more character-relevant, business students, business educators and experienced business professionals in the U.K. agreed that a crucial step would be to bring more positive business role models into lecture rooms and to enlist tutors as character mentors. The role of equal (peer) character friends was not mentioned, however (Huo \& Kristjánsson, 2018). ${ }^{5}$ In response to the possible objection that Aristotle himself confines his specification of (even budding) character friendships to a small number of well brought-up people, and that most 'friendships' in the business world would be what he called 'friendships for utility', available to more agents, it must be pointed out that Aristotle also made a qualitative distinction between two sub-types of utility friendship where one type 'would seem to depend on character, and the other on rules', with the latter being confined to 'mercenary'-type associations, whereas the former is 'more generous' (1985, pp. 233-234) [1162b23-27]). That former type includes the relationships that Aristotle notes often form between 'fellow-voyagers and fellow-soldiers' (1985, p. 224 [1159b27-28]), and he would presumably have wanted to say the same about prospective business partners also.

I revisit briefly some of the 'methods' that learning from friends appear to involve, according to Aristotle, in the final section. However, two observations are in order at the present juncture. The first is that, notwithstanding its historical and philosophical salience, Aristotle's friendship theory leaves many questions unanswered. For example, the frequent allusions to the (character) friend as 'another self' (1985, p. 246 [1166a30-33]; cf. pp. 260 and 265 [1170b6-7; 1172a32-34]) are problematic. It is not entirely clear whether Aristotle is (a) speaking metaphorically, (b) making a moral point about the essential substantive sharing of affection and purpose, and how what is in your best interest is also in your friend's best interest, and vice versa, or (c) making an ontological point about the inherently relational nature of selfhood. If (c) is what he means, that would obviously carry significant ramifications for the very idea of joint decision-making and its ideal qua collective phronesis. Second, what Aristotle says about the educational value of friendships for developing good character and judgement falls short of being an account of the development of collective phronesis. To return to the example of the two business

\footnotetext{
${ }^{5}$ For reasons that remain moot the focus in most current forms of Aristotle-inspired character education (be it for pupils or aspiring professionals) is on the emulation of superior moral exemplars rather than the role of peer character friendships (Hoyos-Valdés, 2018).
} 
ethics students, Aristotle's theory explains how those can contribute to each other's individual phronetic development and prepare them for lives as ethically minded and responsible business professionals. However, he does not address the question of how developmental friendship processes can prepare them for truly joint decision-making, for example, if they decide to open a small business together and run it fully collaboratively through equal, consensual managerial procedures-or how such procedures can add incremental value to the friends' merely aggregated individual phronetic capacities.

To elicit more explicit (if not always fully transparent) Aristotelian views about the value of collective phronesis, we need to turn to his Politics. ${ }^{6}$ I ask readers, throughout the remainder of this section and the following interpretative section to remain mindful of Solomon's (1992) tip that because of the smallness and unique nature of the political entities Aristotle was talking about (Greek city-states), his theory of political governance may carry more immediate implications for the (ethical) running of small business firms or institutions than modern nation states (see also Sison, 2011).

It is worth reproducing here the much-cited and somewhat enigmatic passage by Aristotle in full about what is typically referred to as his 'argument about the wisdom of the multitude' but what Horn (2016) calls 'the accumulation argument':

For it is possible that the many, though not individually [virtuous], ${ }^{7}$ yet when they come together may be better, not individually but collectively, than those who are so, just as public dinners to which many contribute are better than those supplied at one man's cost; for where there are many, each individual, it may be argued, has some portion of virtue and [phronesis], and when they have come together, just as the multitude becomes a single man with many feet and many hands and many senses, so also it becomes one personality as regards [character and thought] (Aristotle, 1944, pp. 221-222 [1281b1-8]), minor amendments made to the translation).

At a later juncture (1944, p. 257 [1286a24-37], Aristotle complements this passage with an observation about the many being less corruptible than the few and also less likely to fall prey, all at the same time, to an overbearing passion like anger. Notice that Aristotle is here going well beyond the message derived from his educational claims

\footnotetext{
${ }^{6}$ For the best overall exegesis of Aristotle's Politics, see Kraut (2002). For a shorter analysis, see Miller (2013).

7 It must be assumed that Aristotle is here referring to fully phronesis-guided virtue.
}

about character friendships and even the message from his passages on individual phronesis in the Nicomachean Ethics, where he observes that 'we enlist partners in deliberation on large issues when we distrust our own ability to discern [the right answer]' (1985, p. 62 [1112b10-11]). The emphasis has now moved from enlisting help from others to (learn how to) choose wisely towards the synergic effect of joint phronetic decision-making.

Somewhat disappointingly, Aristotle backs up those accumulation claims (about the multitude being both ethically and intellectually stronger than the individual ${ }^{8}$ ) simply with a number of Socratic sounding analogies from daily life, rather than enlisting, as he usually does, the views of the many and the wise, and critiquing those. His analogies relate to (a) many cooks improving rather than spoiling the broth; (b) the many adding extra 'limbs' to the individual; (c) the many being better at judging poetry and music than a single critic; (d) great quantities of water being less easily polluted than a small amount; and (e) the 'users' of a product (here governance) being better judges of it than the 'makers'. Bobonich (2015) has subjected those analogies to critical scrutiny, both in themselves and as applied to the specific context of Athenian living, and found them all wanting. That is, none of them, either individually or collectively, comes anywhere close to making a sound case for the collective wisdom of the multitude in terms of governance, especially the way in which the accumulation in question is meant to amplify the multitude's strengths only, but not their many deficiencies also. To move the discussion forward, we need to set the accumulation argument in the context of the overall theoretical argument that Aristotle is making in the Politics, about civic virtue and the specific phronesis of rulers/managers, rather than just relying on folksy analogies.

\section{Interpreting the Accumulation Argument for Collective Phronesis}

Interpreting 'the accumulation argument' correctly, especially in terms of eliciting its implications for business ethics and business practice, is a tall order, not only because the interpretative task has hitherto mostly been confined to a small group of Aristotelian scholars, but also because their interpretations have, in my view, typically highlighted very questionable aspects of the argument-namely, its relevance for ancient and modern democratic theory-rather than its more general implications for the collective phronesis

\footnotetext{
${ }^{8}$ Aristotle seems to be saying that the accumulation of individual capacities can boost both the overall stock of moral and intellectual (phronetic) virtue, beyond the mere aggregation of perspectives (see e.g. Cammack, 2013).
} 
of 'rulers', or what we could call 'collective managerial phronesis'.

Two of the best known economics and political science scholars working on the wisdom of crowds, Hong and Page, begin their study by claiming that in 'describing the benefits of democracy, Aristotle observed that when individuals see distinct parts of the whole, the collective appraisal can surpass that of individuals' (2012, p. 56; italics added). These two are obviously not philosophers. However, philosophers have also perpetuated this received wisdom. For example, Waldron (2005), in a much-cited paper identifying a 'doctrine of the wisdom of the multitude' in Aristotle, pushes the concept in a radically democratic direction. This may seem decidedly odd at first sight since Aristotle was no friend of democracy, famously consigning it - as a seedbed of demagoguery-to one of the perverted forms of government (1944). In response, pro-democracy scholars may argue that Aristotle did defend a more benign form of government, called polity, which bears some of the hallmarks of modern democracies although it was reserved for the rule of the middle class only, leaving out the poorest and least educated. However, as argue below, I doubt that the multitude (plethos) that Aristotle wants to franchise with his accumulation argument even covers all the middle class.

What seems to be forgotten in most of the pro-democracy interpretations is that part of the original passage which talks about the advantage of pooling the resources of those who have 'some portion of virtue and phronesis'. Given that Aristotle believed only a small fraction of people ever develop any sort of phronesis, the accumulation argument may be much more circumscribed and elitist (albeit not necessarily in a negative sense) than it is often made out to be. In the context of the Politics, which is a treatise about the best governance/management of a very small state and who are fit to act as its rulers, I read the accumulation argument as simply stating that it is beneficial for such an entity to have relatively many people, who are already developing or mature phronimoi, coming together to manage it (in default of the earlier-mentioned 'god-among-men' single ruler who does not exist in the real world). The reason for this is that even the best of real-life phronimoi are fallible, and in adding together their intellectual and experiential resources, the benefits of collective phronesis (argued for through Aristotle's various analogies) are activated. In other words, I consider the accumulation argument to be exclusively about the pros of collective phronesis for good management, not

\footnotetext{
${ }^{9}$ For a typology of general managerial phronesis and an overview of the relevant literature, see Steyn and Sewchurran (2021).
}

about the pros of deliberative democratic practices, more broadly speaking. ${ }^{10}$

To substantiate my interpretation, a brief rehearsal of some basic Aristotelian assumptions about the nature and possibility of developing moral and civic virtues is in order. In the Nicomachean Ethics, Aristotle concedes that, sadly, because of defective upbringing, most people do not even reach the level of habituated (non-deliberative) moral virtue, let alone phronetic (i.e. proper phronesis-guided) moral virtue. Instead, most people find themselves somewhere between the levels of incontinence (moral awareness but lack of self-control) and continence (self-control) (1985, p. 190 [1150a15]), and there is even a considerable portion of people below those levels, without any significant moral endowments whatsoever. Aristotle does not mince his words about the non-phronetic masses. Having 'no taste' for the fine and truly pleasant, they have 'no notion' of what it is, and find 'disorderly living' pleasanter than 'sober living' (1985, p. 292 [1179b10], 1944, p. [1319b30-33]). It would be very far-fetched to believe that Aristotle wanted to give this large multitude any seat at the high table, deliberating about the running of the city. That would, by his lights, not constitute an exercise in collective phronesis but rather in collective ignorance (cf. Tsouni, 2019), ${ }^{11}$ just as if we allowed the person with no medical knowledge to evaluate the work of physicians (1944, pp. 226-227 [1282a1-10]).

When it comes to the Politics, where the focus turns from moral to civic virtue, Aristotle relinquishes the strict demands that virtue needs to be phronesis-guided to count as true virtue and also enjoyable for the person actualising it. For 'all ought to possess the goodness [virtue] of a good citizen' (1944, p. 189 [1277a2-4])—albeit at a fairly low level. At this low level, Aristotle is for the most part referring to civic virtue qua mere law-abidingness; and there it suffices that the agent forces herself to act civically in following the law; hence, civic virtue at this level is more akin to continence in the sphere of moral virtue. Aristotle's aversion to conflict shines through in his assumption that even the worst of pervert constitutions is marginally better than no constitution - namely anarchy — and hence 'the many' (namely all citizens) need to be able, at least, to approve of decisions enshrined in law by acting in accordance with them. This is not the same, however, as playing a constitutive part in the actual deliberative process of state governance, as I have been explaining.

\footnotetext{
${ }^{10}$ As Garsten (2013, p. 336) correctly reminds us, the modern assumption that the value of deliberation is somehow grounded in, and confined to, democratic practices would have been alien to Aristotle.

${ }^{11}$ In the words of Thomas Carlyle (cited in Surowiecki, 2004, p. xvi), 'I do not believe in the collective wisdom of individual ignorance'.
} 
For present purposes, it is more important to consider higher forms of civic virtue, confined to rulers, with which Aristotle is more concerned and to which his accumulation argument is evidently tied. For Aristotle, it would be 'absurd' to think that the governance of a state should be in the hands of the base rather than the virtuous (1944, p. 229 [1282a24-27]). ${ }^{12}$ More specifically, Aristotle does not believe any reasonable person can think it acceptable that the proper ruling of a state be in the hands of anyone except the phronimoi; and he would almost certainly have said the same about the management of modern-day business companies, at least those larger than small family-based ones.

Instead of being less demanding than the criteria for moral virtue, the conditions of civic virtue at this managerial level become more demanding. In their decision-making, the rulers need to take into account what is good not only for themselves but for all citizens (1985, p. 154 [1140b7-11]). This means that phronesis at the management level will have a wider scope than phronesis at the level of everyday affairs. Not being a utilitarian, Aristotle does not require ordinary phronetic people to synchronise their decisions with the eudaimonia of all human beings in mind, but simply the people most immediately affected by the decision. However, that all changes once you become a ruler in charge of people; then decision-making becomes about the common interest or the common good (to koine sympheron).

This brings us back to the original question of who comprise the multitude under discussion in the accumulation argument. I hope it is now clearer than before that the multitude Aristotle has in mind, as potential collaborators in ruling, is a fairly small 'multitude', consisting solely of sufficiently educated people (Tsouni, 2019), intellectually and morally: namely, people who at least have some modicum of phronesis to contribute to the governance process. Two of the philosophers involved in Aristotelian exegesis, Bobonich (2015) and Irrera (2010), have suggested something of an intermediary position, according to which non-phronimoi among the public may contribute to management processes because they may be privy to unique information and experiences that even all the relevant phronimoi lack, hence having important 'parts' of virtue and phronesis to add to the mix even if they lack the overall phronetic capacities. I do not think this argument works, at least not in the context of fleshing out the accumulation argument. To be sure, various citizens may be called to the table for guidance and information

\footnotetext{
12 In the final books of the Politics, Aristotle describes the idealistic governance of aristocratic polity where all the citizens are phronimoi and all rule together or in turn. He is at pains to explain that this is a realistic ideal, not utopian such as a god-like-governed monarchy, because it is possible that a self-selected group of phronimoi actually decide to emigrate from an existing state and set up a colony in a new place.
}

before collective decisions are taken, just as business managers may call in workers from the floor for counselling before agreeing on a new company policy. However, this does not thereby mean they have 'parts' of phronesis to contribute to the management process. ${ }^{13}$ Phronesis does, according to Aristotle, have numerous components (see the Sect. "The Components of Collective Managerial Phronesis"), but brute information about facts and brute experiences are not such components; phronesis is much more subtle and sophisticated than that. The basic problem that Aristotle is trying to solve in the Politics is how the quality of state governance can be made to approximate as far as possible to the quality of the utopian god-among-men ruler. His answer is that this is best done by collating the expertise of many phronimoi, at least minimally capable of ruling, because many wise heads are normally better than one, in a non-utopian world.

What explains, then, the staying power of the interpretation that Aristotle is, in his Politics, making an argument in favour of democratic deliberation and participation? ${ }^{14}$ Some of it may simply be wishful thinking; it would have been nice if Aristotle had been a democrat. Some of it may be caused by inattention to modern democratic assumptions that were foreign to Aristotle, such that of the moral equality of all human beings, the idea of human rights, and the belief that individuals are themselves the best judges of their own interests. Finally, some of it may be derived from positive evaluations of various Aristotelian political ideas, many of which are uncharacteristically (for his time) egalitarian, state-interventionist and, to use Nussbaum's provocative

\footnotetext{
13 A reviewer suggested, as a problematic intermediate example, the case of business managers calling in a not very phronetic accountant for consultation before making an important business decision. Does it really matter whether the 'part' contributed by the accountant can be defined as a component of phronesis or not? Well it does, for conceptual purposes at least, if we understand Aristotle's argument to be (as I argue) about the advantages of joint decision-making. Simply providing helpful information to a decision-making process is not the same as being actively involved in the process.

14 None of what I have said above should be interpreted to mean that I reject the historic role that Aristotle has been seen to play in the development of the ideals of deliberative democracy: the school of thought in political theory that claims that political decisions should be the product of fair and reasonable discussion and debate among citizens. I am particularly referring here to work by Waldron (2005) and Schwartzberg (2016). The ideas of a thinker such as Aristotle may help develop a given discourse although they were not originally intended for that purpose. The point I have been making is simply that Aristotle's 'accumulation argument' was originally about what I have called the advantages of 'collective phronesis' rather than what would normally be called 'deliberative democracy' on a modern understanding. Yet the general point he makes about the need to draw on as many sources of experience as possible, before making a decision, clearly allows for various extensions.
} 
(1990) characterisation, 'Scandinavian'. ${ }^{15}$ His strict demands for state-directed-and-funded public education were, for example, revolutionary in ancient Greece. Moderns may simply find it difficult to fathom that a person who was so egalitarian in one way could be so elitist in another.

Once we have got the pro-democracy reading of the Politics out of the way and direct our attention to the real core of the work, which is about how to rule a small unit of management (the city-state) in an ethically informed and phronesisguided way by exploiting the advantages of collective phronesis, we realise that the Politics should more serviceably be read and made use of by business ethicists and business managers than by democratic political theorists.

\section{The Components of Collective Managerial Phronesis}

What are the psycho-moral processes involved in Aristotelian collective managerial phronesis, as specified in the previous section? That is by no means an easy question, for Aristotle says next to nothing about it in the Politics. The only thing we can reasonably do is to revisit his extensive account of the functions of the different phronesis components in the Nicomachean Ethics and then offer speculative hypotheses about how the intra-psychic processes described for individual phronesis could be extended towards collective inter-psychic ones. Before embarking on that task, a few clarificatory remarks are in order.

Aristotle sometimes speaks in the Nicomachean Ethics as if virtue and phronesis are an all-or-nothing affair, and either one possesses the whole set-lock, stock and barrel-or one has none of it. ${ }^{16}$ This is when he is in his Platonic mode of defining concepts with respect to their most fully realised instances. However, it is not difficult to piece together a more nuanced Aristotelian picture, according to which virtuous agents can (a) be strong in one moral virtue and weak in another, (b) possess a moral virtue 'more or less', (c) be strong in one component of moral virtue, for instance the emotional component, but weaker in another, such as putting it into action, and (d) possess already one portion of phronesis (morion phroneseos) but not others (see

\footnotetext{
15 While not as idealistic as Nussbaum, Kraut also draws up a very appealing picture of Aristotle's theory in the Politics as illuminating a political system where 'citizens would value themselves and each other for their qualities as human beings, not for their wealth and power' (Kraut, 2002, p. 481)

16 This assumption and the theory of the 'unity of the virtues' (where each virtue seems to entail all the rest; so what is the need, then, for phronesis?) constitute some of the most problematic features of Aristotle's virtue theory. However, fortunately, he is not consistent on those aberrant features, as indicated below.
}

e.g. Aristotle, 1985, p. 270 [1173a18-22], 1944, pp. 223 and 533 [1281b4-5;1323a27-30]). The power of speech $(\log o s)$ then allows us, in principle at least, to bring these virtue portions into a relationship with different portions from another individual and make them coalesce into a new broader whole (see e.g. Garsten, 2013, p. 343). It is important to understand the 'portions' (morion) of phronesis not as mere fragments or crumbs, but rather as discrete psychological functions, where one ruler/manager can be strong on one but another ruler/manager stronger on another. The natural place to look for those 'portions' is in the detailed account of individual phronesis from the Nicomachean Ethics, from which the following taxonomy of the components/functions of phronesis has been derived. ${ }^{17}$

\section{Constitutive Function}

Phronesis involves the cognitive ability to perceive the ethically salient aspects of a situation and to appreciate these as calling for specific kinds of responses. This ability can be cultivated and amounts to the capacity to 'read' a situation by seeing what is most important or central. We can also refer to this function as moral sensitivity. ${ }^{18}$

\section{Integrative Function}

Through phronesis, an individual integrates different components of a good life, especially in circumstances where different ethically salient considerations, or different kinds of virtues, appear to be in conflict. In some cases, integration may call for a 'blended' or 'synchronised' virtuous response, such as being compassionately honest or honestly compassionate; in other cases, a virtue may have to be put on hold completely in a given situation in light of the overriding requirement of a conflicting virtue.

\section{Blueprint Function}

The integrative work of phronesis operates in conjunction with the agent's overall understanding of the kinds of things

\footnotetext{
17 The following description and figure draw on Darnell et al. (2019) and Kristjánsson et al. (2021). This Aristotelian model has also been corroborated in all essentials by Wright et al. (2021). Interestingly, this model bears a striking resemblance to the so-called 'Level of Connection' in a model worked out independently (and not explicitly indebted to Aristotle) for business education programmes by Intezari and Pauleen (2013).

18 In fact, Aristotle posits a subsidiary intellectual virtue of comprehension (sunesis) which is about grasping the essentials of a situation (1985, p. 164 [1143a1-18]). Further enlightenment on this sensitivity part of phronesis can be gleaned by reading some of the current literature on moral imagination and how it relates to managerial decisionmaking, see esp. Werhane (1999).
} 


\section{A Neo-Aristotelian Model of Wise (Phronetic) Moral Decision-Making}

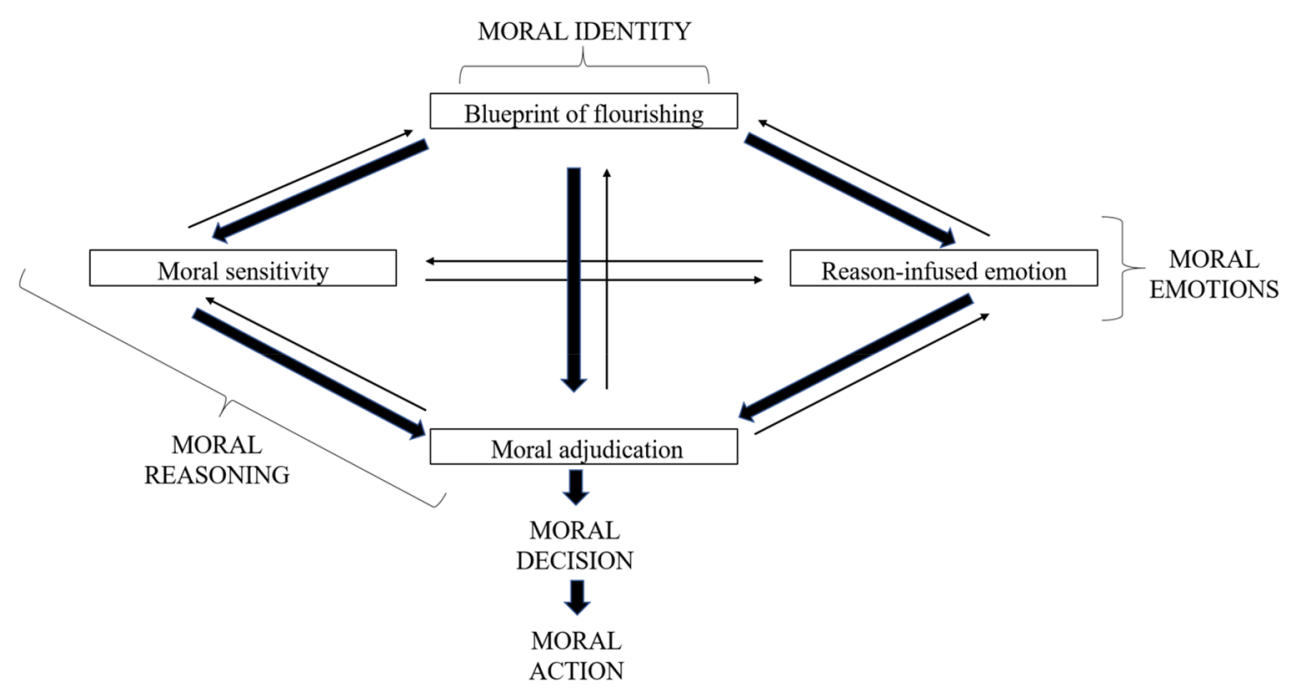

Fig. 1 A neo-Aristotelian model of wise (phronetic) moral decision-making

that matter for a flourishing life: the agent's own ethical identity, aims and aspirations, her understanding of what it takes to live and act well, and her need to live up to the standards that shape and are shaped by her understanding and experience of what matters in life. This amounts to a blueprint of flourishing.

\section{Emotional Regulative Function}

Individuals foster their emotional wellbeing through phronesis by bringing their emotional responses into line with their understandings of the ethically salient aspects of their situation, their judgement and their recognition of what is at stake. For example, a phronimos might recognise that her appraisal of the situation is problematic, giving rise to an emotional response that is inappropriate and needs to be corrected. For this reason, we can also refer to this function as that of infusing emotion with reason. Figure 1 illustrates the overall conceptualisation of individual Aristotelian phronesis. ${ }^{19}$

\footnotetext{
19 It is worth noting, however, that (as can be seen in Fig. 1), the components do not refer to psycho-moral capacities that are completely independent of one another and can be turned 'up' or 'down' in isolation. For example, the cultivation of moral sensitivity is likely to impact in various ways upon the capacity for moral reasoning about the situations identified with greater sensitivity. For a further elaboration of Fig. 1, see Kristjánsson et al. (2021).
}

Let us now try to rhapsodise about how these functions might operate and be enriched at the collective level. ${ }^{20}$ Consider a group of recent business graduates who, as fellow students and friends, decide to open an ethically responsible business company together upon completion of their studies. As business ethics enthusiasts, and being virtue-ethically oriented, these friends and, now, business colleagues have been impressed by Aristotle's ideal of collective phronesis and want to enact it at the managerial level in the running of their company. All decisions will be taken on a collective basis and in line with the functions of phronetic decisionmaking. How could this work out and add incremental value in practice?

Let us begin this time with the blueprint function. Bear in mind that what Aristotle was after here is not an individual's idiosyncratic 'authentic', 'autonomous' sense of 'personal purpose', as such a conceptualisation did not originate until the Enlightenment (although his insistence on the individualisation of virtue might seem to suggest an embryonic form of those ideals). Rather, what is at stake is the overarching vision of the purpose (telos) of human life in general and a person's moral identity as it relates that purpose to her conception of flourishing (eudaimonia). This is where the internal motivation for phronetic decision-making comes from qua deliberated desires (Aristotle, 1985, p. 64 [1113a12]), complementing the motivation from external sources: namely, the conative aspects of the specific moral

\footnotetext{
${ }^{20}$ Steyn and Sewchurran (2021) helpfully elicit some relevant subcomponents/functions (or what they call 'modes' and 'characteristics') of managerial phronesis.
} 
and civic virtues that phronesis synthesises. Given that our business entrepreneurs are all virtue-ethically minded, they will most likely share a general common vision of flourishing, as well as the ethically responsible goals of their company. However, through a process of presenting their vision to one another, reflecting upon it and modifying it in light of the conclusions of their dialogue, they have a chance to come up with a blueprint that is more coherent and universal, and less easily corruptible, than any single person's vision.

Turning next to the constitutive function (aka moral sensitivity), it is well known that people's perceptions of the same event differ considerably. One of the colleagues may notice a moral danger lurking in one of the business strategies that the group have come up with, while this has escaped the notice of others. This function of phronesis is perhaps the one most obviously augmentable through collective practice.

The benefits of collective work on the emotional regulation function are more controversial. Aristotle's empirical observation that it is difficult for a whole group to be roused by a wayward emotion at the same time (1944, p. 257 [1286a31-36]) is not exactly in line with contemporary social psychological research about the effects of infectious mass hysteria (cf. Cammack, 2013, p. 187). However, it is easy to understand where Aristotle is coming from. If one of the business partners becomes overly upset by a setback, or angry about a rebuff from a potential buyer, some of the other members of the group are likely to be of a less emotional disposition and thus able to calm her down. Similarly, if one of them loses courage and confidence in the venture, the rest may be able to help her muster it up again.

Finally, the adjudicative function is the crucible through which potentially conflicting considerations are reconciled and channelled into ethically responsible action. As Garsten (2013, pp. 329-330) explains well, Aristotle has a strong view on this. He does not only believe that collective phronesis can help coordinate independent deliberations from different agents, but rather that it can bring those deliberations 'into relation with one another in a manner that yields actions attributable to the whole of which each of them is a part'. We must remember here that Aristotle's conception of selfhood was arguably more interdependent than the one we are used to in today's Western cultures (Markus \& Kitayama, 1991) — witness for example Aristotle's earlier-cited remarks about the character friend as 'another self'. ${ }^{21}$

Some of the above musings about the synergies of collective managerial phronesis may sound like little more than

\footnotetext{
${ }^{21}$ It may well be that Confucian forms of virtue ethics come closer to Aristotle's self-concept than most modern Western forms, even so-called 'neo-Aristotelian' ones (cf. Alzola et al., 2020; Huo \& Kristjánsson, 2020).
}

platitudes about the working of human collaboration in general, probably better accounted for by more sophisticated models from modern moral psychology (see e.g. Akrivou $\&$ Scalzo, 2020) or some more fancy academic labels, such as 'intersubjective co-creativity'. While that may be true, we must be mindful of the uniqueness of the Aristotelian conception of collective phronesis, in that its system of mutual checks and balances aims not so much at favourable collaborative outcomes-although those matter also-as for the ethical betterment of the agents involved. Phronesis may be an intellectual virtue, but it is inseverably tied to the moral virtues and the overall aspiration to (help each other) become a better person. As Aristotle himself puts it, eupraxia (doing well, inter alia as a result of phronesis) and eudaimonia are in the end one and the same thing (1944, p. 547 [1325a22-23]).

\section{Some Practical Business Applications}

This article has so far proceeded at a fairly high level of abstraction, perhaps higher than Aristotle himself would have liked. After all, the purpose of an inquiry into virtue theory, such as this one, is ultimately 'not to know what virtue is, but to become good, since otherwise the inquiry would be of no benefit to us' (1985, p. 35 [1103b27-29]). It behoves us, therefore, to suggest some more practical applications for business ethics education and practice.

\section{Business Ethics Education}

The primary goal of Aristotle's ethical and political treatises is educational. At the early adulthood level-where most business ethics students are situated - the fundamental virtue to be taught is phronesis, as one will expect the students to have more or less been habituated into the moral virtues already; and if they have not, there is not much that can be done in a single university course to rectify that anyway. Teaching phronesis does not just mean teaching about phronesis but rather providing students with practical opportunities to hone it through emulation and guided practice. This is why Aristotle would have been saddened by the alreadycited finding that business students, at least in the U.K., do not consider themselves to have had the opportunity to develop phronesis in their studies, not even within discrete business ethics classes (Huo \& Kristjánsson, 2018).

None of this will come as a surprise to virtue-ethically minded business ethics educators (see e.g. Steyn \& Sewchurran, 2021). What I have argued in this article, however, is that to do full justice to Aristotle's account of phronesis, it is not enough to study the Nicomachean Ethics on moral and intellectual virtues. We also need to pay attention to the account of collective managerial phronesis in the Politics, 
and how that links to the actualisation of civic virtues, especially for those who plan to run organisational entities, be it a city or a business company. The problem is that Aristotle does not offer any new methods of instruction in the Politics for the cultivation of collective phronesis beyond those already adumbrated in his other works for virtue development more generally. As suggested by business students themselves (Huo \& Kristjánsson, 2018), the role of moral exemplars will be invaluable, but in order to facilitate the positive impact of those role models on students, in terms of building up their collective phronesis, the exemplars must be brought into direct contact with the students and given a chance to interact with them constructively.

No less important for the development of collective phronesis would be the method of forming small teams of likeminded business ethics students-one could call them phronesis dyads or triads - and give them tasks that call for joint decision-making in the service of a higher ethical good. As Aristotle noted long before Dewey, 'learning by doing' is the fundamental method for moral education. Some guidance on how such student teams could operate can be gleaned from remarks Aristotle makes about the development of character friendships through the mutual 'moulding' of sensitivities (1985, pp. 266 and 208 [1172a11-14 and 1155a15-16]). These arguably involve, in the first instance, the establishment of an emotional connection that is uniquely conducive to moral learning in terms of character improvement.

The pride of place that Aristotle gives to emotions as part of the good life is well known (Kristjánsson, 2018). While he does not single out emotions that are specific to character friendships, some candidates readily suggest themselves. One is trust and, most notably here, mutual trust. A moral learner can also place trust in an elevated role model, but in most cases such trust will not be mutual; the standard role model may not even be personally acquainted with the learner. Trust is an essential emotion in many non-friendship-based social relationships, such as in various complex market exchanges, but there it is grounded in quite different motivational and dispositional structures to friendship and manifests itself differently. The unique feature of mutual trust, which is grounded in psychological intimacy and soulmateship, is that it steadies the mind, by providing what could be called existential security, and lowers psychological barriers of self-disclosure and self-receptivity, some of which are inimical to any kind of moral learning.

We must not lose sight, however, of the difference between character friendship and collective phronesis that was already underlined: namely, that the former is typically about helping the friend to make informed decisions, whereas the latter is about facilitating the processes of truly joint decision-making. The friends may simply stare each other in the eye and give each other mental support (which is fine, as far as it goes), but partners in collective phronesis look forward, towards the same moral vision, and try to achieve it collaboratively. Moreover, even if one wanted to exploit the empirical evidence on character friendship in the service of collective phronesis, very little of it unfortunately exists. The huge empirical mountain of literature on friendships notwithstanding (a lot of which is cited in the volume edited by Hojjat \& Moyer, 2017), only a miniscule part of it deals with character friendships as a method of moral education (Kristjánsson, 2020). That lacuna is obviously even more striking in the case of collective phronesis itself, as the concept is still not theoretically developed enough, let alone oven-ready for rigorous empirical scrutiny (yet see Schwarz \& Lappalainen, 2020). So, for the time being, our best bet is to rely on the literature on phronesis development more generally, although that literature is also fairly meagre. ${ }^{22}$

\section{Business Practice}

Understandably, the construct of collective phronesis is not better developed for actual business practice than it is for business (ethics) education. One significant exception should be mentioned here, however, of a business scholar who has made constructive use of this very concept in his theorising: Ikujiro Nonaka (see e.g. Nonaka et al., 2008). Best known for his work on the knowledge-creating firm, Nonaka draws on a number of Eastern and Western theoretical constructs, such as tacit learning, soft dialectical communication methods and, most notably for present purposes, collective phronesis, which Nonaka seems to have derived through his own creative extension of Aristotle's concept from the Nicomachean Ethics, rather than gleaning it from its more specific context in the Politics. Nonaka's work is, in my view, a goldmine for business scholars interested in further developing the concept of collective phronesis, especially in managerial contexts, and it means that they do not need to reinvent the wheel but can take Nonaka's writings as their starting point.

Particularly illuminating is Nonaka's setting of collective phronesis in the context of the Japanese concept of $b a$, which is ill-translatable into English but refers to an ethos or a space in motion in which knowledge can be created (see further in Scalzo \& Fariñas, 2018). While the ultimate goal is to create such space within every company, Nonaka sets the bar quite high by suggesting that, initially, companies need to create opportunities for their executives to cultivate character and integrity by interacting with scholars from the humanities and political science to build up a humanist vision of the true goals of leadership. One may harbour

\footnotetext{
22 The best overview, in the context of phronesis-friendly business education, is probably that by Grossmann (2021). Intezari and Pauleen (2013) also provide a helpful summary table of methods (p. 168). Cf. Kristjánsson (2021).
} 
doubts about the willingness of typical practically minded CEOs in the West to initiate such crossover discussions within their companies. Indeed, although I have already cited Solomon (1992) twice on similarities between ancient Greek city-states and the modern firm, someone might point out that, structural likeness aside, the culture (ethos) in those city-states was radically different from today's corporate culture. That said, the corporate climate changes rapidly, and if a collective-phronesis forum, such as the one suggested by Nonaka, really produces results in terms of knowledge creation that benefits firms, perhaps such forums will one day become standard business practice. Interestingly, Guiso et al. (2015) argue that corporate culture in the West may already be shifting in a more ethical and humanist direction, driven by performance measures which show that such culture simply pays off.

In all events, Nonaka's focus on the necessary climate to foster collective phronesis within business companies leads us straight to discourses that are much better researched and evidenced than any applications of Aristotle's own repertoire. These are the discourses about team dynamics and ideal team composition. What we do know is that teams perform best when they are composed of individuals who are different in term of capacities (referred to as 'cognitive diversity') but still not too different so as to foster polarisation (see e.g. Surowiecki, 2004, Chaps. 2 and 8). ${ }^{23}$ It is reasonable to suppose that these general findings will carry over into any study involving the creation of collective-phronesis forums or company teams.

\section{Under the Umbrella of Organisational Wisdom}

I said earlier that collective phronesis could not be equated with organisational wisdom, as the latter construct is much broader, involving many non-deliberative variables. However, as we learn from Nonaka's work, the deliberative aspects of collective phronesis can only awaken and thrive within a climate that is conducive to innovation and knowledge creation, and that climate includes certain mindsets of relevant actors that incorporate tacit knowledge which itself is not necessarily deliberative. To find a home somewhere, each academic pursuit requires the relevant pigeon-holing, and as 'organisational wisdom' is a better entrenched concept in the business literature than 'collective phronesis', it might do the latter construct good to be studied under the umbrella of organisational wisdom (see e.g. Rooney,

\footnotetext{
${ }^{23}$ See Becker et al. 2017, for a more rigorous analysis of network dynamics; and Mannes et al. 2012, for some general findings about the psychology of crowd wisdom.
}

2013). ${ }^{24}$ This might also help connect research on collective phronesis to an even broader concept of social-practice research (Flyvbjerg, 2001), which again represents a leaf taken straight out of Aristotle's book.

James Surowiecki remarks that the more important a decision is, 'the more important it is that it not be left in the hands of a single person' $(2004$, p. 222). This article has perhaps constituted little more than a sustained reflection on that theme. However, I hope the main lesson learned is that there are under-exploited resources within Aristotle's Politics enabling us to think this issue through more constructively than often happens to be the case in the current literature.

\section{Declarations}

Conflict of interest The author declares that he has no conflict of interest.

Human and Animal Rights This article does not contain any studies with human participants or animals performed by any of the authors.

Informed Consent This article does not contain any studies with human participants and no humans are involved in this article.

Open Access This article is licensed under a Creative Commons Attribution 4.0 International License, which permits use, sharing, adaptation, distribution and reproduction in any medium or format, as long as you give appropriate credit to the original author(s) and the source, provide a link to the Creative Commons licence, and indicate if changes were made. The images or other third party material in this article are included in the article's Creative Commons licence, unless indicated otherwise in a credit line to the material. If material is not included in the article's Creative Commons licence and your intended use is not permitted by statutory regulation or exceeds the permitted use, you will need to obtain permission directly from the copyright holder. To view a copy of this licence, visit http://creativecommons.org/licenses/by/4.0/.

\section{References}

Kristjánsson, K. (2007). Aristotle, emotions, and education. Ashgate/ Routledge.

Kristjánsson, K. (2015). Phronesis as an ideal in professional medical ethics: Some preliminary positionings and problematics. Theoretical Medicine and Bioethics, 36(5), 299-320.

Kristjánsson, K. (2018). Virtuous emotions. Oxford University Press.

Kristjánsson, K. (2020). Aristotelian character friendship as a method of moral education. Studies in Philosophy and Education, 39(4), 349-364.

Kristjánsson, K. (2021). Twenty-two testable hypotheses about phronesis: Outlining an educational research programme. British Educational Research Journal, in press. Retrieved from https://berajournals.onlinelibrary.wiley.com/doi/epdf/10.1002/berj.3727.

Kristjánsson, K., Fowers, B., Darnell, C., \& Pollard, D. (2021). Phronesis (practical wisdom) as a type of contextual integrative thinking.

\footnotetext{
${ }^{24}$ See also Hays's helpful model of dynamic organisational wisdom (2013, p. 135).
} 
Review of General Psychology, in press. Retrieved from https:// journals.sagepub.com/doi/full/10.1177/10892680211023063.

Akrivou, K., \& Scalzo, G. (2020). In search of a fitting moral psychology for practical wisdom: The missing link for virtuous management. Business Ethics: A European Review, 29(S1), 33-44.

Alzola, M., Hennig, A., \& Romar, E. (2020). Thematic symposium editorial: Virtue ethics between East and West. Journal of Business Ethics, 165(2), 177-189.

Ames, M. C. F. D. C., Serafim, M. C., \& Zappellini, M. B. (2020). Phronesis in administration and organizations: A literature review and future research agenda. Business Ethics: A European Review, 29(S1), 65-83.

Annas, J. (2011). Intelligent virtue. Oxford University Press.

Aristotle. (1944). Politics, (H. Rackham., W. Heinemann, Trans.).

Aristotle. (1985). Nicomachean ethics, (T. Irwin, Trans.). Hackett Publishing.

Beadle, R., \& Moore, G. (2018). MacIntyre on virtue and organization. In T. Angier (Ed.), Virtue ethics (pp. 323-340). Routledge.

Becker, J., Brackbill, D., \& Centola, D. (2017). Network dynamics of social influence in the wisdom of crowds. Proceedings of the National Academy of Sciences, 114(26), 5070-5076.

Bobonich, C. (2015). Aristotle, political decision making, and the many. In T. Lockwood \& T. Samaras (Eds.), Aristotle's politics: A critical guide (pp. 142-162). Cambridge University Press.

Cammack, D. (2013). Aristotle on the virtue of the multitude. Political Theory, 41(2), 175-202.

Caputo, J. D. (1993). Against ethics. Indiana University Press.

Conroy, M., Malik, A. Y., Hale, C., Weir, C., Brockie, A., \& Turner, C. (2021). Using practical wisdom to facilitate ethical decisionmaking: A major empirical study of phronesis in the decision narratives of doctors. BMC Medical Ethics, 22(16), 1-13.

Darnell, C., Gulliford, L., Kristjánsson, K., \& Paris, P. (2019). Phronesis and the knowledge-action gap in moral psychology and moral education: A new synthesis? Human Development, 62(3), $101-129$.

Flyvbjerg, B. (2001). Making social science matter. Cambridge University Press.

Fowers, B. J., Carroll, J. S., Leonhardt, N. D., \& Cokelet, B. (2021). The emerging science of virtue. Perspectives on Psychological Science, 16(1), 118-147.

Galton, F. (1907). Vox populi (the wisdom of crowds). Nature, 75 , $450-451$

Garsten, B. (2013). Deliberating and acting together. In M. Deslauriers \& P. Destrée (Eds.), The Cambridge companion to Aristotle's politics (pp. 324-349). Cambridge University Press.

Grossmann, I. (2021). Evidence-based training of wisdom in business and management: Use of scientific insights about malleability of practical wisdom for rigorous interventions. In B. Schwartz, C. Bernacchio, C. González-Cantón, \& A. Robson (Eds.), Handbook of practical wisdom in business and management (pp. 1-20). Springer.

Grossmann, I., Weststrate, N. M., Ardelt, M., Brienza, J. P., Dong, M., Ferrari, M., Fournier, M. A., Hu, C. S., Nusbaum, H. C., \& Vervaeke, J. (2020). The science of wisdom in a polarized world: Knowns and unknowns. Psychological Inquiry, 31(2), 103-133.

Guiso, L., Sapienza, P., \& Zingales, L. (2015). The value of corporate culture. Journal of Financial Economics, 117(1), 60-76.

Hays, J. (2013). Transformation and transcendence for wisdom: The emergence and sustainment of wise leaders and organizations. In W. Küpers \& D. J. Pauleen (Eds.), A handbook of practical wisdom: Leadership, organization and integral business practice (pp. 134-154). Routledge.

Hojjat, M., \& Moyer, A. (2017). The psychology of friendship. Oxford University Press.

Hong, L., \& Page, S. E. (2012). Some microfoundations of collective wisdom. In H. Landemore \& J. Elster (Eds.), Collective wisdom: Principles and mechanisms (pp. 56-71). Cambridge University Press.
Horn, C. (2016). Individual competence and collective deliberation in Aristotle's Politics. In C. Arruzza \& D. Nikulin (Eds.), Philosophy and political power in antiquity (pp. 94-113). Brill.

Hoyos-Valdés, D. (2018). The notion of character friendship and the cultivation of virtue. Journal for the Theory of Social Behaviour, 48(1), 66-82.

Huo, Y., \& Kristjánsson, K. (2018). Why is there lack of growth in character virtues? An insight into business students across British business schools In D. Carr (Ed.), Cultivating moral character and virtue in professional practice (pp. 207-221). Routledge.

Huo, Y., \& Kristjánsson, K. (2020). An explorative study of virtues in ethical consumption from a Confucian perspective in an urban-ruralfringe in China. Business Ethics and Leadership, 4(4), 105-122.

Intezari, A., \& Pauleen, D. J. (2013). Students of wisdom: An integral meta-competencies theory of practical wisdom. In W. Küpers \& D. J. Pauleen (Eds.), A handbook of practical wisdom: Leadership, organization and integral business practice (pp. 155-174). Routledge.

Irrera, E. (2010). Being a good ruler in a deviant community: Aristotle's account of the polity. Polis, 27(1), 58-79.

Kaldjian, L. C. (2014). Practicing medicine and ethics: Integrating wisdom, conscience, and goals of care. Cambridge University Press.

Kemmis, S. (2012). Phronesis, experience, and the primacy of practice. In E. A. Kinsella \& A. Pitman (Eds.), Phronesis as professional knowledge: Practical wisdom in the professions (pp. 147-161). Sense Publishers.

Koehn, D. (1995). A role for virtue ethics in the analysis of business practice. Business Ethics Quarterly, 5(3), 533-539.

Kraut, R. (2002). Aristotle: Political philosophy. Oxford University Press.

Küpers, W., \& Pauleen, D. J. (Eds.). (2013). A handbook of practical wisdom: Leadership, organization and integral business practice. Routledge.

Landemore, H. (2012). Collective wisdom: Old and new. In H. Landemore \& J. Elster (Eds.), Collective wisdom: Principles and mechanisms (pp. 1-20). Cambridge University Press.

MacIntyre, A. (1981). After virtue. University of Notre Dame Press.

MacIntyre, A., \& Dunne, J. (2003). Alasdair MacIntyre on education: In dialogue with Joseph Dunne. Journal of Philosophy of Education, $36(1), 1-19$

Mannes, A. E., Larrick, R. P., \& Soll, J. B. (2012). The social psychology of the wisdom of crowds. In J. I. Krueger (Ed.), Frontiers of social psychology: Social judgment and decision making (pp. 227-242). Psychology Press.

Markus, H. R., \& Kitayama, S. (1991). Culture and self: Implications for cognition, emotion, and motivation. Psychological Review, 98(2), 224-253.

Miller, F. (2013). The rule of reason. In M. Deslauriers \& P. Destrée (Eds.), The Cambridge companion to Aristotle's Politics (pp. 38-66). Cambridge University Press.

Nonaka, I., Toyama, R., \& Hirata, T. (2008). Managing flow: A process theory of the knowledge-based firm. Palgrave Macmillan.

Nussbaum, M. C. (1990). Aristotelian social democracy. In R. B. Douglass, G. M. Mara, \& H. S. Richardson (Eds.), Liberalism and the good (pp. 203-252). Routledge.

Rooney, D. (2013). Being a wise organizational researcher: Ontology, epistemology and axology. In W. Küpers \& D. J. Pauleen (Eds.), $A$ handbook of practical wisdom: Leadership, organization and integral business practice (pp. 79-98). Routledge.

Russell, D. C. (2009). Practical intelligence and the virtues. Oxford University Press.

Scalzo, G., \& Fariñas, G. (2018). Aristotelian phronesis as a key factor for leadership in the knowledge-creating company according to Ikujiro Nonaka. Cuadernos De Administración, 31(57), 19-44.

Schwarz, E., \& Lappalainen, J. H. (2020). Collective phronesis? An investigation of collective judgement and professional action. In R. 
Giovagnoli \& R. Lowe (Eds.), The logic of social practices (pp. 23-35). Springer.

Schwartz, B., \& Sharpe, K. E. (2010). Practical wisdom: The right way to do the right thing. Riverhead Books.

Schwartz, B., Bernacchio, C., González-Cantón, C., \& Robson, A. (Eds.). (2021). Handbook of practical wisdom in business and management. Springer.

Schwartzberg, M. (2016). Aristotle and the judgment of the many: Equality, not collective quality. The Journal of Politics, 78(3), 733-745.

Sellman, D. (2012). Reclaiming competence for professional phronesis. In E. A. Kinsella \& A. Pitman (Eds.), Phronesis as professional knowledge: Practical wisdom in the professions (pp. 115-130). Sense Publishers.

Sison, A. J. G. (2011). Aristotelian citizenship and corporate citizenship: Who is a citizen of the corporate polis? Journal of Business Ethics, 100(1), 3-9.

Sison, A. J. G., Ferrero, I., \& Guitián, G. (2018). Business ethics: A virtue ethics and common good approach. Routledge.

Solomon, R. C. (1992). Corporate roles, personal virtues: An Aristotelian approach to business ethics. Business Ethics Quarterly, 2(3), 317-339.

Sperber, D., \& Mercier, H. (2012). Reasoning as social competence. In H. Landemore \& J. Elster (Eds.), Collective wisdom: Principles and mechanisms (pp. 368-392). Cambridge University Press.
Steyn, F., \& Sewchurran, K. (2021). Towards a grainier understanding of how to encourage morally responsible leadership through the development of phronesis: A typology of managerial phronesis. Journal of Business Ethics, 170(4), 673-695.

Surowiecki, J. (2004). The wisdom of crowds: Why the many are smarter than the few. Abacus.

Tsouni, G. (2019). Political wisdom as the virtue of the ruler and the defense of democratic participation in Aristotle's Politics. Philosophie für die Polis. Akten des 5. internationalen Kongresses der Gesellschaft für Antike Philosophie in Zürich (pp. 279-299). De Gruyter.

Waldron, J. (2005). The wisdom of the multitude: Some reflections on Book III, Chapter 11 of Aristotle's Politics. In R. Kraut \& S. Skultety (Eds.), Aristotle's politics: Critical essays (pp. 145-165). Rowman and Littlefield.

Werhane, P. (1999). Moral imagination and moral decision-making. Oxford University Press.

Wright, J., Warren, M., \& Snow, N. (2021). Understanding virtue: Theory and measurement. Oxford University Press.

Publisher's Note Springer Nature remains neutral with regard to jurisdictional claims in published maps and institutional affiliations. 